\title{
NRAGE promotes the malignant phenotype of hepatocellular carcinoma
}

\author{
DAI SHIMIZU ${ }^{1}$, MITSURO KANDA ${ }^{1}$, HIROYUKI SUGIMOTO ${ }^{1}$, SATOSHI SUEOKA ${ }^{1}$, HIDEKI TAKAMI ${ }^{1}$, \\ KAZUHIRO EZAKA $^{1}$, YURI TANAKA ${ }^{1}$, RYOJI HASHIMOTO ${ }^{1}$, YUKIYASU OKAMURA ${ }^{2}$, NAOKI IWATA ${ }^{1}$, \\ CHIE TANAKA ${ }^{1}$, SUGURU YAMADA ${ }^{1}$, TSUTOMU FUJII ${ }^{1}$, GORO NAKAYAMA ${ }^{1}$, MASAHIKO KOIKE ${ }^{1}$, \\ SHUJI NOMOTO ${ }^{3}$, MICHITAKA FUJIWARA $^{1}$ and YASUHIRO KODERA ${ }^{1}$ \\ ${ }^{1}$ Department of Gastroenterological Surgery (Surgery II), Nagoya University Graduate School of Medicine, Nagoya, \\ Aichi 466-8550; ${ }^{2}$ Department of Hepatobiliary-Pancreatic Surgery, Shizuoka Cancer Center, Shizuoka 411-8777; \\ ${ }^{3}$ Department of Surgery, Aichi-Gakuin University School of Dentistry, Nagoya, Aichi 464-8651, Japan
}

Received February 25, 2015; Accepted January 5, 2016

DOI: $10.3892 / \mathrm{ol} .2016 .4120$

\begin{abstract}
Hepatocellular carcinoma (HCC) is a fatal disease, primarily due to the limited effective therapies available for patients with advanced or recurrent stages of the disease. Therefore, in order to improve patient prognosis, it is important to identify an informative biomarker for HCC progression, as well as a molecular target for therapy. Neurotrophin receptor-interacting melanoma antigen-encoding protein (NRAGE), a member of the type II melanoma-associated antigen family, mediates apoptosis and cell death through interactions with a wide range of proteins, and is implicated as a tumor suppressor or oncoprotein depending on cell type. However, the role of NRAGE in HCC is currently unknown, therefore, the present study aimed to identify the underlying function of NRAGE in HCC tumorigenesis. Resected tumor and non-cancerous liver tissues from 151 patients with HCC, alongside HCC cell lines, were analyzed by polymerase chain reaction and immunohistochemical techniques to determine NRAGE expression levels, as well as the expression levels of potential genes encoding interacting proteins. It was demonstrated that the expression levels of NRAGE mRNA correlated significantly with those of apoptosis-antagonizing transcription factor $(A A T F)$, and were not affected by cirrhosis in non-cancerous liver tissues when compared to elevated levels in HCC tissues. The expression patterns of NRAGE protein and mRNA were consistent among 30 representative specimen pairs. Furthermore, increased NRAGE expression in patients with HCC correlated significantly with a shorter
\end{abstract}

Correspondence to: Dr Mitsuro Kanda, Department of Gastroenterological Surgery (Surgery II), Nagoya University Graduate School of Medicine, 65 Tsurumai-cho, Showa-ku, Nagoya, Aichi 466-8550, Japan

E-mail:m-kanda@med.nagoya-u.ac.jp

Key words: hepatocellular carcinoma, neurotrophin receptor-interacting melanoma antigen-encoding protein, expression, progression, apoptosis-antagonizing transcription factor disease-specific survival time, and was identified as an independent prognostic factor via multivariate analysis (hazard ratio, 2.23; 95\% confidence interval, 1.06-3.83; $\mathrm{P}=0.020$ ). Therefore, the results of the present study indicated that increased NRAGE expression affects HCC progression via its interaction with $A A T F$, and may represent a novel biomarker and molecular target for the treatment of HCC.

\section{Introduction}

Hepatocellular carcinoma (HCC) is one of the most prevalent malignant tumors, with high rates of mortality and morbidity $(1,2)$. The worldwide incidence of HCC is $\sim 1,000,000$ cases per year and is equivalent to its mortality rate (3). Furthermore, HCC ranks as the third highest cause of cancer-associated mortality (4). Such statistics are largely explained by the difficulties faced when diagnosing HCC, with diagnosis often only confirmed once the disease is at a late stage and palliative care is the only treatment option available. An important strategy to improve patient outcome involves the identification of disease risk factors and the maintenance of vigilant surveillance of high-risk individuals to allow for recognition of the disease at a stage that is responsive to treatment with curative intent. Therefore, it is fundamental that high-risk groups are identified, followed by successful implementation of a surveillance program and recall protocol following any abnormal findings (5-8). Progress has been made in identifying molecular markers for the initiation and progression of HCC that will likely increase the rate of early and potentially life-saving diagnoses (9-12). The expanding amount of knowledge regarding the molecular foundations of HCC makes it increasingly clear that successful therapy requires treatment tailored to the individual patient (8).

Melanoma-associated antigens (MAGEs), members of the cancer/testis antigen family that consists of $>50$ proteins, are divided into two types, MAGE-I and MAGE-II, dependent on varying gene structures and tissue-specific expression patterns $(13,14)$. The MAGE-I subgroup consists of products yielded by numerous $\mathrm{X}$ chromosome clustered genes, including $M A G E-A,-B$ and $-C$, which are typically expressed in cancer 
cells of various origins, but not in adult tissues, with the exception of germ-line cells in the placenta, ovaries and testes $(15,16)$. By contrast, the MAGE-II subgroup, including $M A G E-D$ variants, do not have defined chromosome clustering and are cancer non-specific, with near universal expression in normal adult tissues and germ-line cells $(14,16,17)$. MAGE proteins, as tumor-associated antigens, have attracted increasing attention regarding the development of vaccine-based immunotherapy for the treatment of cancer (18). Our strategy for addressing this issue involves detailed analysis of the literature to identify potential markers and targets for therapy of HCC (15). For example, a previous meta-analysis indicated that glypican-3, des- $\gamma$-carboxyprothrombin, $\alpha$-L-fucosidase and vascular endothelial growth factor may serve as suitable serological markers for HCC (19). Meta-analyses are incisive and may potentially be more informative compared with omic surveys that are expensive, technology-intensive and arguably more time-consuming. This lead the current study to focus on the 86-kDa NRAGE protein, also known as MAGE-D1, which is encoded by the NRAGE gene located on the $\mathrm{X}$ chromosome (20-22). Cells of diverse embryonic and adult tissues, particularly those of the nervous system, express NRAGE, which subsequently interacts with proteins that regulate cell adhesion and migration, the cell cycle, cell differentiation, apoptosis and gene transcription (22-24). However, little is understood regarding the physiological relevance of these interactions.

NRAGE serves a role in the process of apoptosis through interactions with the p75 neurotrophin receptor (p75NTR) (25) and apoptosis-antagonizing transcription factor (AATF) $(26,27)$. As NRAGE interacts with proteins with diverse functions, it is not unexpected that its effects are cell-type specific. For example, the downregulation of NRAGE transcription serves an important function in apoptosis, and when expressed ectopically, NRAGE inhibits the proliferation of breast cancer cells (27). Furthermore, downregulation of NRAGE in colorectal cancer is associated with a negative clinical course $(24,28,29)$. By contrast, NRAGE functions as an oncogene in esophageal and lung cancers $(22,30)$. Yang et al (22) demonstrated that the overexpression of $N R A G E$ exerts tumor-promoting effects by interacting with the DNA polymerase III domain of proliferating cell nuclear antigen (PCNA) and consequently inhibits K48-polyubiquitin chain-mediated proteasome degradation of PCNA in esophageal cancer. However, to the best of our knowledge, there are currently no studies concerning NRAGE expression in $\mathrm{HCC}$ or its role in the pathogenesis of this disease. Therefore, the aim of the present study was to assess the clinical significance of $N R A G E$ expression in HCC, as well as its relevance as a novel biomarker for tumor progression.

\section{Materials and methods}

Sample collection. The HCC cell lines (Hep3B, HepG2, HLE, HLF, HuH1, HuH2, HuH7, PLC/PRF/5 and SK-Hep1) were obtained from the American Type Culture Collection (Manassas, VA, USA). All cell lines were cultured in Dulbecco's modified Eagle's Medium (Sigma-Aldrich, St. Louis, MO, USA), supplemented with $10 \%$ fetal bovine serum at $37^{\circ} \mathrm{C}$ in an atmosphere containing $5 \% \mathrm{CO}_{2}(6)$. The primary $\mathrm{HCC}$ tissues and the corresponding non-cancerous tissues were collected from 151 patients with $\mathrm{HCC}$ who had undergone liver resection at the Nagoya University Hospital (Nagoya, Japan) between January 1998 and July 2012. The specimens were classified histologically according to the criteria published in the Classification of Malignant Tumours, Union for International Cancer Control (UICC) (31). Clinicopathological data were collected from medical records, and written informed consent for the use of clinical samples and data was obtained from all patients, as required by the Institutional Review Board of Nagoya University, Japan (32).

Reverse transcription-quantitative polymerase chain reaction $(R T-q P C R)$. Expression levels of mRNA in all samples were analyzed using RT-qPCR, which was performed using an Applied Biosystems StepOne Plus (Thermo Fisher Scientific, Inc., Waltham, MA, USA) in triplicate. Total RNA $(10 \mu \mathrm{g})$ isolated from the HCC cell lines, and the 151 primary HCC specimens and corresponding adjacent non-cancerous tissues, was used as the template for the synthesis of complementary DNA. RT-qPCR was performed using the SYBR ${ }^{\circledR}$ Green PCR Core Reagents kit (Applied Biosystems; Thermo Fisher Scientific, Inc.) and specific primers for NRAGE (Hokkaido System Science Co., Ltd., Tokyo, Japan) as follows: One cycle at $95^{\circ} \mathrm{C}$ for $10 \mathrm{~min}, 40$ cycles at $95^{\circ} \mathrm{C}$ for $5 \mathrm{sec}$ and $60^{\circ} \mathrm{C}$ for $30 \mathrm{sec}$. For standardization, glyceraldehyde-3-phosphate dehydrogenase (GAPDH) mRNA (TaqMan GAPDH Control Reagents; Applied Biosystems; Thermo Fisher Scientific, Inc.) was quantified in each sample. Expression levels are presented as the value of NRAGE mRNA divided by the value of GAPDH mRNA $(33,34)$. Expression levels of mRNAs were normalized by the serially diluted standards (35). AATF, p75NTR and PCNA encode proteins that may interact with NRAGE, and the specific primers (Hokkaido System Science Co., Ltd.) used for each of these genes are listed in Table I.

Immunohistochemistry (IHC). IHC was performed to determine the expression and localization of NRAGE in 30 representative well-preserved HCC samples. Formalin-fixed, paraffin-embedded tissue samples were dewaxed twice in xylene for $5 \mathrm{~min}$, rehydrated sequentially using a graded series of alcohol concentrations (100, 90 and $70 \%$ ) for 2 min each and treated with $3 \%$ $\mathrm{H}_{2} \mathrm{O}_{2}$ to inhibit endogenous peroxidases. Antigen retrieval was performed by incubating the sections 5 times in citrate buffer $(10 \mathrm{mM})$ at $95^{\circ} \mathrm{C}$ for $5 \mathrm{~min}$. The samples were then washed with phosphate-buffered saline, followed by a 10-min incubation with biotinylated goat anti-rabbit IgG secondary antibody (Histofine SAB PO(R) kit; Code 424032; Nichirei Corporation, Tokyo, Japan) for $5 \mathrm{~min}$ to limit non-specific reactivity, and incubated for $1 \mathrm{~h}$ with a rabbit polyclonal anti-human NRAGE antibody (catalog no., LS-C100414; LifeSpan BioSciences, Inc., Seattle, WA, USA) in a 1:200 dilution with ChemMateT antibody diluent (Dako Japan Co., Ltd., Tokyo, Japan). The samples were then washed with phosphate-buffered saline, followed by a 10-min incubation with biotinylated goat anti-rabbit IgG secondary antibody (Histofine SAB-PO(R) kit; Nichirei Corporation) in a 1:1,000 dilution with ChemMateT antibody dilutent. Subsequently, the sections were incubated for $1 \mathrm{~min}$ 
Table I. Primers and annealing temperatures.

\begin{tabular}{|c|c|c|c|}
\hline Gene & Oligo sequence $\left(5^{\prime}-3^{\prime}\right)$ & Product size, bp & Annealing temperature, ${ }^{\circ} \mathrm{C}$ \\
\hline \multicolumn{4}{|l|}{$N R A G E$} \\
\hline Forward & GATTCCCTCAGACCTTTGC & 170 & 60 \\
\hline Reverse & GAAGGAATCTGAGGCTTCAG & & \\
\hline \multicolumn{4}{|l|}{$A A T F$} \\
\hline Forward & ACAAAGGTGGCCCAGAATTT & 103 & 62 \\
\hline Reverse & TGGAAAAGCAACTCTTCCTGA & & \\
\hline \multicolumn{4}{|l|}{ p75NTR } \\
\hline Forward & CTGCTGCTGTTGCTGCTTCT & 98 & 60 \\
\hline Reverse & CAGGCTTTGCAGCACTCAC & & \\
\hline \multicolumn{4}{|l|}{ PCNA } \\
\hline Forward & TGCAAGTGGAGAACTTGGAA & 128 & 58 \\
\hline Reverse & TCAGGTACCTCAGTGCAAAAG & & \\
\hline \multicolumn{4}{|l|}{$G A P D H$} \\
\hline Forward & GAAGGTGAAGGTCGGAGTC & 226 & 60 \\
\hline Probe & CAAGCTTCCCGTTCTCAGCC & & \\
\hline Reverse & GAAGATGGTGATGGGATTTC & & \\
\hline
\end{tabular}

NRAGE, neurotrophin receptor-interacting melanoma antigen-encoding protein; AATF, apoptosis-antagonizing transcription factor; p75NTR, p75 neurotrophin receptor; PCNA, proliferating cell nuclear antigen; GAPDH, glyceraldehyde-3-phosphate dehydrogenase.

A

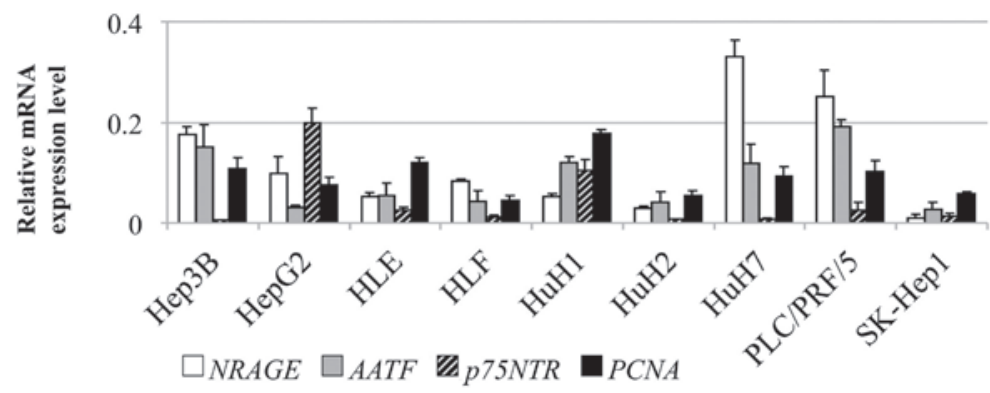

$\mathbf{B}$
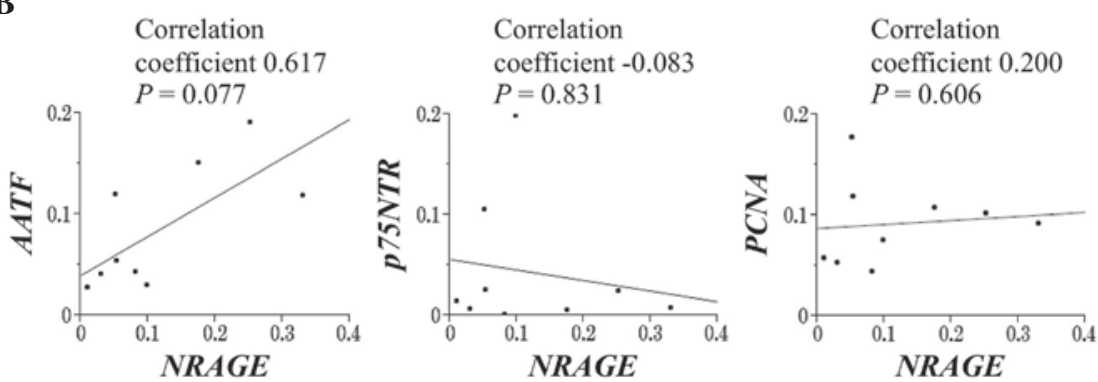

Figure 1. Analysis of NRAGE mRNA expression in the HCC cell lines. (A) Levels of NRAGE mRNA and its putative interacting partners in the HCC cell lines. Error bars indicate the standard deviation of three biological replicates. (B) Analysis of the correlation between NRAGE mRNA level and those of its putative interacting partners $A A T F, p 75 N T R$ and $P C N A . N R A G E$, neurotrophin receptor-interacting melanoma antigen-encoding protein; HCC, hepatocellular carcinoma; $A A T F$, apoptosis-antagonizing transcription factor; $p 75 N T R$, p75 neurotrophin receptor; $P C N A$, proliferating cell nuclear antigen.

with liquid 3,3'-diaminobenzidine (Nichirei Corporation) to detect antigen-antibody complexes. Staining of NRAGE was evaluated using vessels as internal controls. To avoid bias when interpreting data, specimens were randomized and coded prior to analysis by two independent observers who were uninformed of the status of the samples. Each observer evaluated all specimens at least twice within a given time interval to minimize intraobserver variation $(36,37)$.

Statistical analysis. The significance of the association between the levels of NRAGE mRNA and the clinicopathological features was evaluated using the $\chi^{2}$ test, and differences between 
Table II. Association between NRAGE mRNA levels and clinicopathological parameters of 151 hepatocellular carcinoma patients.

\begin{tabular}{lcr}
\hline Clinicopathological parameters & Increased expression of NRAGE mRNA, $\mathrm{O}$ & Others, \\
\hline Age, years & 34 & 33 \\
$<65$ & 59 & 25 \\
$\geq 65$ & & 52 \\
Gender & 74 & 6 \\
Male & 19 & 4 \\
Female & & 36 \\
Background of liver & 6 & 18 \\
Normal & 51 & 36
\end{tabular}

Child-Pugh classification

A

B

Hepatitis virus

Absent

HBV

$\mathrm{HCV}$

PIVKA II, mAU/ml

Tumor multiplicity

Tumor size, $\mathrm{cm}$

Differentiation

Well

Moderate to poor

Serosal infiltration

Formation of capsule

Septum formation 
Table II. Continued.

\begin{tabular}{lcc}
\hline Clinicopathological parameters & Increased expression of NRAGE mRNA, $\mathrm{n}$ & Others, $\mathrm{n}$ \\
\hline UICC pathological stage & & 0.919 \\
I & 59 & 35 \\
II & 23 & 16 \\
III & 11 & 7 \\
\hline
\end{tabular}

${ }^{a} \mathrm{P}<0.05$. HCC, hepatocellular carcinoma; NRAGE, neurotrophin receptor-interacting melanoma antigen-encoding protein; HBV, hepatitis B virus; $\mathrm{HCV}$, hepatitis $\mathrm{C}$ virus; AFP, $\alpha$-fetoprotein; PIVKA, protein induced by vitamin K antagonists; UICC, Union for International Cancer Control.

Table III. Prognostic factors of 151 patients with hepatocellular carcinoma.

\begin{tabular}{|c|c|c|c|c|c|c|c|}
\hline \multirow[b]{2}{*}{ Variable } & \multirow[b]{2}{*}{$\mathrm{n}$} & \multicolumn{3}{|c|}{ Univariate analysis } & \multicolumn{3}{|c|}{ Multivariate analysis } \\
\hline & & Hazard ratio & $95 \% \mathrm{CI}$ & P-value & Hazard ratio & $95 \% \mathrm{CI}$ & P-value \\
\hline Age $\geq 65$ years & 84 & 1.92 & $1.07-3.57$ & $0.030^{\mathrm{a}}$ & 1.39 & $0.75-2.65$ & 0.301 \\
\hline Male gender & 126 & 1.27 & $0.60-3.13$ & 0.553 & & & \\
\hline Cirrhosis of liver & 4 & 1.58 & $0.88-2.81$ & 0.123 & & & \\
\hline Child-Pugh classification B & 11 & 0.93 & $0.28-2.32$ & 0.889 & & & \\
\hline $\mathrm{AFP}>20 \mathrm{ng} / \mathrm{ml}$ & 70 & 1.90 & $1.07-3.42$ & $0.029^{\mathrm{a}}$ & 1.30 & $0.70-2.44$ & 0.790 \\
\hline PIVKA II >40 mAU/ml & 93 & 2.10 & $1.14-4.07$ & $0.016^{\mathrm{a}}$ & 1.12 & $0.55-2.40$ & 0.770 \\
\hline Tumor multiplicity & 34 & 2.09 & $1.11-3.76$ & $0.023^{\mathrm{a}}$ & 1.32 & $0.67-2.53$ & 0.416 \\
\hline Tumor size $\geq 3.0 \mathrm{~cm}$ & 104 & 2.20 & $1.13-4.71$ & $0.020^{\mathrm{a}}$ & 1.87 & $0.82-4.64$ & 0.140 \\
\hline Well-differentiated tumor & 35 & 0.55 & $0.25-1.10$ & 0.095 & & & \\
\hline Invasive growth & 24 & 1.44 & $0.69-2.76$ & 0.318 & & & \\
\hline Serosal infiltration & 37 & 2.51 & $1.32-4.61$ & $0.006^{\mathrm{a}}$ & 1.53 & $0.76-2.95$ & 0.225 \\
\hline Formation of capsule & 104 & 1.05 & $0.57-2.02$ & 0.884 & & & \\
\hline Infiltration to capsule & 83 & 1.20 & $0.67-2.18$ & 0.537 & & & \\
\hline Septum formation & 98 & 0.87 & $0.49-1.60$ & 0.651 & & & \\
\hline Vascular invasion & 37 & 3.40 & $1.87-6.07$ & $<0.001^{\mathrm{a}}$ & 2.24 & $1.12-4.41$ & $0.022^{\mathrm{a}}$ \\
\hline Increased $N R A G E$ expression & 93 & 2.42 & $1.27-4.99$ & $0.006^{\mathrm{a}}$ & 2.23 & $1.06-3.83$ & $0.020^{\mathrm{a}}$ \\
\hline
\end{tabular}

Univariate analysis was performed using the log-rank test. Multivariate analysis was performed using the Cox proportional hazards model. ${ }^{\text {a }}<0.05$. CI, confidence interval; AFP, $\alpha$-fetoprotein; PIVKA, protein induced by vitamin $\mathrm{K}$ antagonists; NRAGE, neurotrophin receptor-interacting melanoma antigen-encoding protein.

groups were evaluated using the Mann-Whitney U test. Correlations between the level of NRAGE mRNA and encoding AATF, p75NTR and PCNA, as well as those of pre-operative serum tumor markers, were analyzed using Spearman's rank correlation coefficient. Disease-specific survival rates were calculated using the Kaplan-Meier method, and the differences in survival curves were evaluated using the generalized Wilcoxon rank-sum test. $\mathrm{P}<0.05$ was considered to indicate a statistically significant difference. All statistical analyses were performed using $\mathrm{JMP}^{\circledR}$ software, version 10 (SAS Institute Inc., Cary, NC, USA).

\section{Results}

Analysis of NRAGE, AATF, p75NTR and PCNA mRNA expression in HCC cell lines. The relative levels of NRAGE mRNA and those of its putative interacting partners, $A A T F$, p75NTR and PNCA, in the HCC cell lines are presented in
Fig. 1A. Heterogeneity was observed in the NRAGE mRNA levels between $9 \mathrm{HCC}$ cell lines, which correlated significantly with those of $A A T F$ (correlation coefficient, 0.617 ), whereas no significant correlation was observed between the expression of NRAGE and $p 75 N T R$ or PCNA (Fig. 1B).

Patient characteristics. The ages of the 151 patients ranged from 34-84 years (mean \pm standard deviation, $64.7 \pm 9.8$ years), and the male to female ratio was 5:1. A total of 37 and 84 patients were infected with hepatitis B and C virus, respectively. The numbers of patients with a normal liver, chronic hepatitis or cirrhosis were 10, 87 and 54, respectively. When classified according to the UICC's tumor-node-metastasis classification, 94, 39 and 18 patients were in stages I, II and III, respectively.

Analysis of NRAGE and AATF mRNA levels in surgically resected liver tissues. There were no significant differences 
A

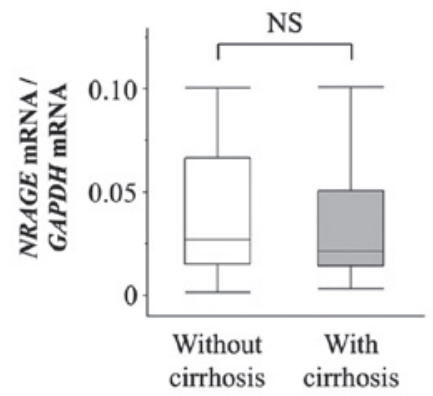

B

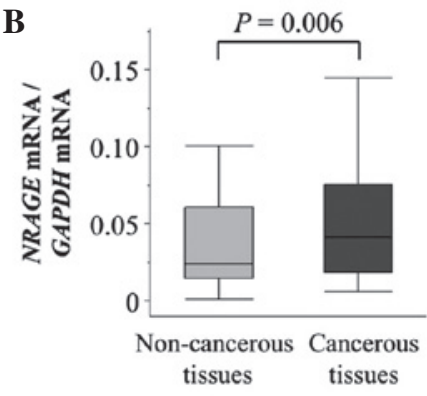

\section{C}
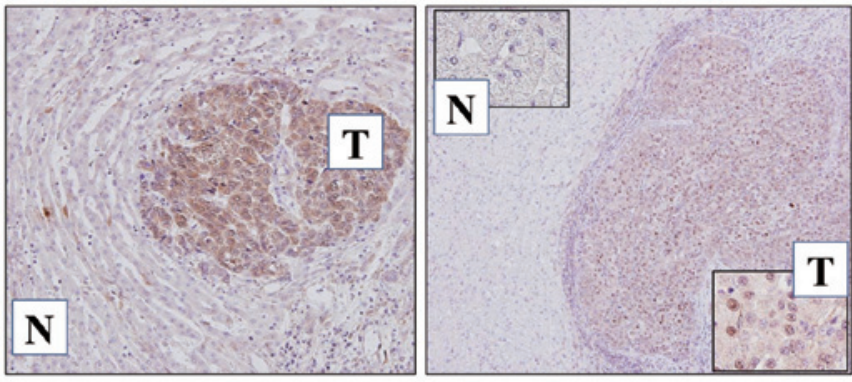

D

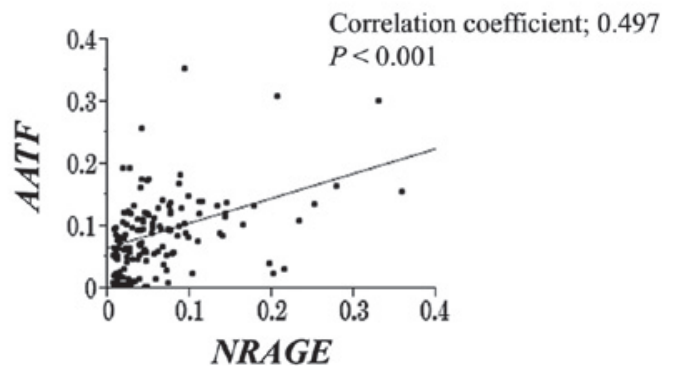

Figure 2. Analysis of NRAGE expression in the liver tissues. (A) NRAGE mRNA levels did not differ significantly between non-cancerous liver tissues of patients with and without cirrhosis. (B) NRAGE mRNA levels were significantly elevated in the HCC tissues compared with the corresponding non-cancerous liver tissues. (C) Two representative cases demonstrating strong immunoreactivity of NRAGE specific to the HCC tissues (magnification: Left, x200; right, $\mathrm{x} 100$; and inset, $\mathrm{x} 400$ ). (D) Analysis of the correlation between NRAGE and AATF mRNA levels in the HCC tissues. HCC, hepatocellular carcinoma; NRAGE, neurotrophin receptor-interacting melanoma antigen-encoding protein; GAPDH, glyceraldehyde-3-phosphate dehydrogenase; N, normal; T, tumor; AATF, apoptosis-antagonizing transcription factor.

A

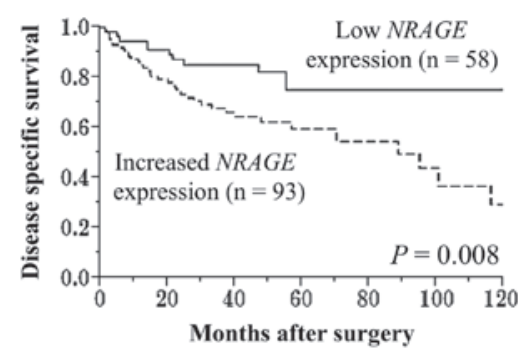

B

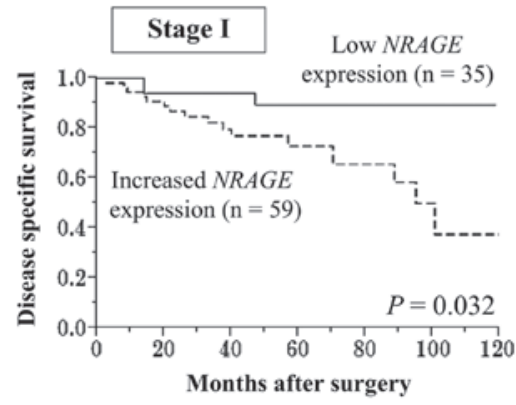

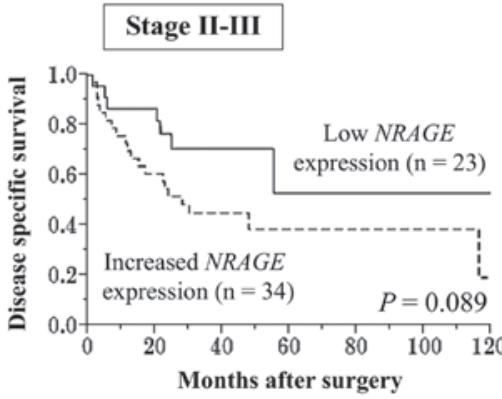

Figure 3. Patient survival analysis. (A) Patients with increased expression of $N R A G E$ mRNA experienced significantly shorter disease-specific survival times. (B) Subgroup analysis as a function of Union for International Cancer Control tumor-node-metastasis staging. Increased levels of NRAGE mRNA were associated with shorter survival times in patients with stages I or II-III HCC. HCC, hepatocellular carcinoma; NRAGE, neurotrophin receptor-interacting melanoma antigen-encoding protein. 
observed in the NRAGE mRNA levels in the non-cancerous tissue samples between patients with or without cirrhosis (Fig. 2A). However, the mean level of NRAGE mRNA in the HCC tissues was significantly higher compared with that in the corresponding normal tissues $(\mathrm{P}=0.006$; Fig. 2B).

IHC analysis was conducted to determine whether NRAGE expression correlated with NRAGE mRNA levels in the tumor and non-cancerous tissues. Representative images showing strong staining intensities of NRAGE in cancer tissues are presented in Fig. 2C. The expression patterns of $N R A G E$ protein and mRNA in the HCC and non-cancerous tissues were consistent among 30 representative pairs of specimens. It was observed that the level of NRAGE and $A A T F$ mRNA was directly correlated, consistent with results of the analysis of the HCC cell lines (Fig. 2C).

Clinical significance of NRAGE mRNA expression. Tissue sections were assigned to two groups (high and low expression) according to their level of NRAGE mRNA. The high and low expression groups included 93 and 58 patients, respectively. The high expression group was associated with increased age and an $\alpha$-fetoprotein level of $>20 \mathrm{ng} / \mathrm{ml}(\mathrm{P}=0.014$ and $\mathrm{P}=0.020$, respectively; Table II $)$. The disease-specific survival time of the patients was significantly shorter in the high expression group compared with the low expression group (5-year survival rate, 60 vs. $75 \%$; $\mathrm{P}=0.008$; Fig. 3A). Subgroup analysis according to UICC staging indicated that the disease-specific survival curves showed a similar tendency of differences between high and low NRAGE expression groups in each disease stage (Fig. 3B). Multivariate analysis identified vascular invasion and increased NRAGE expression as independent prognostic factors (hazard ratios, 2.24 and 2.23, respectively; Table III).

\section{Discussion}

Originally identified by Salehi et al (25) in a two-hybrid screen utilizing $p 75 N T R$ as bait, NRAGE is a signaling cascade component that mediates apoptosis by interacting with $p 75 N T R$ to antagonize its association with the nerve growth factor receptor tropomyosin receptor kinase A. Studies have indicated that NRAGE promotes apoptosis through the ubiquitination of $A A T F(26,27)$, therefore suggesting that $N R A G E$ functions as a tumor suppressor by inducing tumor cell apoptosis. However, overexpression of NRAGE accelerates the proliferation and migration of esophageal cancer cells via interactions with PCNA. A genome-wide association study demonstrated that the initiation of $N R A G E$ signals through the $J N K$ pathway is associated with non-small cell lung cancer $(22,30)$. Xue et al (38) identified an association between elevated NRAGE expression and the increased radioresistance of esophageal carcinoma cells. Such studies indicate that $N R A G E$ functions to inhibit or promote oncogenesis depending on cell type, leading to the rationale behind the present study.

The current study demonstrated that NRAGE mRNA levels positively correlated with those of $A A T F$, but not those of $p 75 N T R$ or PCNA. The presence of cirrhosis had a minimal affect on NRAGE expression, and NRAGE mRNA levels were significantly higher in the HCC tissues compared with the corresponding non-cancerous tissues; this suggests that NRAGE is involved in hepatocarcinogenesis or the subsequent progression of HCC.

Multivariate analysis of disease-specific survival time following curative hepatectomy and subgroup analysis, according to UICC staging, identified that increased NRAGE mRNA expression in the HCC tissues functioned as an independent prognostic factor. These results indicate that NRAGE serves as a tumor promoting factor, and that the levels of $N R A G E$ mRNA in resected primary lesions may function as a biomarker for the progression of HCC. Furthermore, the results of IHC analysis demonstrated that NRAGE expression correlated with mRNA level, subsequently indicating the physiological significance of the latter. Therefore, future investigation into the function of NRAGE in HCC may be facilitated using RT-qPCR analysis of NRAGE mRNA levels.

In conclusion, NRAGE mediates the progression of HCC and may serve as a novel biomarker for the malignant phenotype of the disease. The present study indicated that the analysis of $N R A G E$ expression may enhance the clinical management of HCC. For example, the levels of NRAGE mRNA in liver biopsies or surgically resected tissues may facilitate risk stratification of patients with HCC, and may also serve as a criterion for determining the most appropriate therapy tailored to individual patients. Furthermore, the findings of the current study demonstrate promise for the development of novel therapies for HCC that employ small molecules or antibodies that target $N R A G E$ and its interacting partners, including $A A T F$. Research to further investigate the signaling pathways that are regulated by or function through $N R A G E$ may expose alternative targets for the treatment of HCC.

\section{References}

1. Shiraha H, Yamamoto K and Namba M: Human hepatocyte carcinogenesis (review). Int J Oncol 42: 1133-1138, 2013.

2. Bruix J, Gores GJ and Mazzaferro V: Hepatocellular carcinoma: Clinical frontiers and perspectives. Gut 63: 844-855, 2014.

3. Yang JD and Roberts LR: Hepatocellular carcinoma: A global view. Nat Rev Gastroenterol Hepatol 7: 448-458, 2010.

4. GLOBOCAN. Estimated Cancer Incidence, Mortality and Prevalence Worldwide in 2012. Stomach Cancer, 2012.

5. Zhao YJ, Ju Q and Li GC: Tumor markers for hepatocellular carcinoma. Mol Clin Oncol 1: 593-598, 2013.

6. Kanda M, Sugimoto H, Nomoto S, Oya H, Hibino S, Shimizu D, Takami H, Hashimoto R, Okamura Y, Yamada S, et al: B-cell translocation gene 1 serves as a novel prognostic indicator of hepatocellular carcinoma. Int J Oncol 46: 641-648, 2015.

7. Flores A and Marrero JA: Emerging trends in hepatocellular carcinoma: Focus on diagnosis and therapeutics. Clin Med Insights Oncol 8: 71-76, 2014.

8. Giannelli G, Rani B, Dituri F, Cao Y and Palasciano G: Moving towards personalised therapy in patients with hepatocellular carcinoma: The role of the microenvironment. Gut 63: 1668-1676, 2014.

9. Kanda M, Nomoto S, Okamura Y, et al: Detection of metallothionein $1 \mathrm{G}$ as a methylated tumor suppressor gene in human hepatocellular carcinoma using a novel method of double combination array analysis. Int J Oncol 35: 477-483, 2009.

10. Miki D, Ochi H, Hayes CN, Aikata H and Chayama K: Hepatocellular carcinoma: Towards personalized medicine. Cancer Sci 103: 846-850, 2012.

11. Khare S, Zhang Q and Ibdah JA: Epigenetics of hepatocellular carcinoma: Role of microRNA. World J Gastroenterol 19: 5439-5445, 2013.

12. Kanda M, Nomoto S, Oya H, Takami H, Hibino S, Hishida M, Suenaga M, Yamada S, Inokawa Y, Nishikawa Y, et al: Downregulation of DENND2D by promoter hypermethylation is associated with early recurrence of hepatocellular carcinoma. Int J Oncol 44: 44-52, 2014. 
13. Chomez P, De Backer O, Bertrand M, De Plaen E, Boon T and Lucas S: An overview of the MAGE gene family with the identification of all human members of the family. Cancer Res 61: 5544-5551, 2001.

14. Tseng HY, Chen LH, Ye Y, Tay KH, Jiang CC, Guo ST, Jin L, Hersey P and Zhang XD: The melanoma-associated antigen MAGE-D2 suppresses TRAIL receptor 2 and protects against TRAIL-induced apoptosis in human melanoma cells. Carcinogenesis 33: 1871-1881, 2012.

15. Takami H, Kanda M, Oya H, Hibino S, Sugimoto H, Suenaga M, Yamada S, Nishikawa Y, Asai M, Fujii T, et al: Evaluation of MAGE-D4 expression in hepatocellular carcinoma in Japanese patients. J Surg Oncol 108: 557-562, 2013.

16. Sang M, Wang L, Ding C, Zhou X, Wang B, Wang L, Lian Y and Shan B: Melanoma-associated antigen genes - an update. Cancer Lett 302: 85-90, 2011.

17. Oya H, Kanda M, Takami H, Hibino S, Shimizu D, Niwa Y, Koike M, Nomoto S, Yamada S, Nishikawa Y, et al: Overexpression of melanoma-associated antigen D4 is an independent prognostic factor in squamous cell carcinoma of the esophagus. Dis Esophagus 28: 188-195, 2015.

18. Chang CC, Campoli M, Luo W, Zhao W, Zaenker KS and Ferrone S: Immunotherapy of melanoma targeting human high molecular weight melanoma-associated antigen: Potential role of nonimmunological mechanisms. Ann NY Acad Sci 1028: 340-350, 2004

19. Hussein TD: Serological tumor markers of hepatocellular carcinoma: A meta-analysis. Int J Biol Markers 30: e32-e42, 2015.

20. Jordan BW, Dinev D, LeMellay V, Troppmair J, Gotz R, Wixler L, Sendtner M, Ludwig S and Rapp UR: Neurotrophin receptor-interacting mage homologue is an inducible inhibitor of apoptosis protein-interacting protein that augments cell death. J Biol Chem 276: 39985-39989, 2001.

21. Wang X, Gao X and Xu Y: MAGED1: Molecular insights and clinical implications. Ann Med 43: 347-355, 2011

22. Yang Q, Ou C, Liu M, Xiao W, Wen C and Sun F: NRAGE promotes cell proliferation by stabilizing PCNA in a ubiquitin-proteasome pathway in esophageal carcinomas. Carcinogenesis 35: 1643-1651, 2014.

23. Barker PA and Salehi A: The MAGE proteins: Emerging roles in cell cycle progression, apoptosis, and neurogenetic disease. J Neurosci Res 67: 705-712, 2002.

24. Du Q, Zhang Y, Tian XX, Li Y and Fang WG: MAGE-D1 inhibits proliferation, migration and invasion of human breast cancer cells. Oncol Rep 22: 659-665, 2009.

25. Salehi AH, Roux PP, Kubu CJ, Zeindler C, Bhakar A, Tannis LL, Verdi JM and Barker PA: NRAGE, a novel MAGE protein, interacts with the p75 neurotrophin receptor and facilitates nerve growth factor-dependent apoptosis. Neuron 27: 279-288, 2000.

26. Di Certo MG, Corbi N, Bruno T, Iezzi S, De Nicola F, Desantis A Ciotti MT, Mattei E, Floridi A, Fanciulli M and Passananti C: NRAGE associates with the anti-apoptotic factor Che-1 and regulates its degradation to induce cell death. J Cell Sci 120 : $1852-1858,2007$
27. Passananti $\mathrm{C}$ and Fanciulli $\mathrm{M}$ : The anti-apoptotic factor Che-1/AATF links transcriptional regulation, cell cycle control, and DNA damage response. Cell Div 2: 21, 2007.

28. Krämer BF, Schoor O, Krüger T, Reichle C, Müller M, Weinschenk T, Hennenlotter J, Stenzl A, Rammensee HG and Stevanovic S: MAGED4-expression in renal cell carcinoma and identification of an HLA-A*25-restricted MHC class I ligand from solid tumor tissue. Cancer Biol Ther 4: 943-948, 2005.

29. Zeng ZL, Wu WJ, Yang J, Tang ZJ, Chen DL, Qiu MZ, Luo HY, Wang ZQ, Jin Y, Wang DS and Xu RH: Prognostic relevance of melanoma antigen D1 expression in colorectal carcinoma. J Transl Med 10: 181, 2012.

30. Lee D, Lee GK, Yoon KA and Lee JS: Pathway-based analysis using genome-wide association data from a Korean non-small cell lung cancer study. PLoS One 8: e65396, 2013.

31. Sobin LH, Gospodarowicz MK and Wittekind C (eds): International Union Against Cancer. TNM Classification of Malignant Tumors. 7th edition. Wiley-Blackwell, New York, 2009.

32. Kanda M, Shimizu D, Nomoto S, Hibino S, Oya H, Takami H, Kobayashi D, Yamada S, Inokawa Y, Tanaka C, et al: Clinical significance of expression and epigenetic profiling of TUSC1 in gastric cancer. J Surg Oncol 110: 136-144, 2014.

33. Kanda M, Nomoto S, Oya H, Shimizu D, Takami H, Hibino S, Hashimoto R, Kobayashi D, Tanaka C, Yamada S, et al: Dihydropyrimidinase-like 3 facilitates malignant behavior of gastric cancer. J Exp Clin Cancer Res 33: 66, 2014.

34. Kanda M, Shimizu D, Nomoto S, Takami H, Hibino S, Oya H, Hashimoto R, Suenaga M, Inokawa Y, Kobayashi D, et al: Prognostic impact of expression and methylation status of DENN/MADD domain-containing protein 2D in gastric cancer. Gastric Cancer 18: 288-296, 2015.

35. Kubista M, Andrade JM, Bengtsson M, Forootan A, Jonák J, Lind K, Sindelka R, Sjöback R, Sjögreen B, Strömbom L, et al: The real-time polymerase chain reaction. Mol Aspects Med 27: 95-125, 2006

36. Kanda M, Nomoto S, Oya H, Hashimoto R, Takami H, Shimizu D, Sonohara F, Kobayashi D, Tanaka C, Yamada S, et al: Decreased expression of prenyl diphosphate synthase subunit 2 correlates with reduced survival of patients with gastric cancer. J Exp Clin Cancer Res 33: 88, 2014.

37. Kanda M, Nomoto S, Okamura Y, Hayashi M, Hishida M, Fujii T, Nishikawa Y, Sugimoto H, Takeda S and Nakao A: Promoter hypermethylation of fibulin 1 gene is associated with tumor progression in hepatocellular carcinoma. Mol Carcinog 50: 571-579, 2011.

38. Xue XY, Liu ZH, Jing FM, Li YG, Liu HZ and Gao XS: Relationship between NRAGE and the radioresistance of esophageal carcinoma cell line TE13R120. Chin J Cancer 29: 900-906, 2010. 